\title{
Cancer risk due to obesity among a university student population
}

\author{
Mary Jane Miller* \\ University of Guam, School of Education, Foundations and Educational Research, USA
}

\begin{abstract}
One of the most frequently cited controllable risk factors associated with cancer is that of excess body weight, and obesity has been shown to have a high association with occurrences of a number of cancer types. This study is designed to examine overweight and obesity rates among the student population attending University of Guam, particularly as influenced by diet and exercise, then to look at these outcomes in light of what research shows to be the impact of obesity on the risk of cancer. The ultimate goal is to address possible behavioral changes that may benefit these university age students in an effort to lower cancer risks.
\end{abstract}

\section{Introduction}

Of the numerous risk factors that contribute to occurrences of cancer among adults, some are immutable such as genetics, age, and unintentional exposure to environmental pollutants. Other factors, however, are within an individual's ability to influence or control and the risks can be altered by changes in behavior. One of the most frequently cited controllable risk factors associated with cancer is that of excess body weight. Obesity has been shown to have a high association with occurrences of a number of cancer types $[1,2]$.

This study is designed to examine overweight and obesity rates among the student population attending University of Guam, particularly as influenced by diet and exercise, then to look at these outcomes in light of what research shows to be the impact of obesity on the risk of cancer. The ultimate goal is to address possible behavioral changes that may benefit these university age students in an effort to lower cancer risks.

\section{What is obesity}

In all parts of the world where starvation and food scarcity are not a problem, obesity has grown to be a major issue. The World Health Organization has estimated that nearly two billion people in the world today are overweight or obese, and the incidence and degree of obesity among adults, adolescents and children continues to grow [3]. Obesity rates may be particularly significant for residents of Guam, a Pacific Island in Micronesia, as an article in the Pacific Daily News states that five of the top eight heaviest populations worldwide are found in the Pacific Islands, including Micronesia [4].

When a person is overweight or obese, it means that they have too much body fat in relation to lean body tissue, such as muscle [5]. Researchers usually measure obesity based on Body Mass Index or BMI [6]. A formula is used to calculate how much fat a person has by comparing height to weight, and sometimes takes age into account [7]. A person is considered overweight if he has a BMI equal to or greater than 25 and obese if he has a BMI equal to or greater than 30 [8]. The percent of overweight and obese American college students was nearly $30 \%$ in the fall of 2011 [9] but a 2017 article in the Journal of Nutrition
Education and Behavior said that the percent of obese college students has now risen to almost $41 \%$ [10].

There are many factors that can contribute to obesity and any age. Contributing factors include genetics, hormones, environment, emotional issues, and cultural norms. People who are overweight have a higher risk of many serious health conditions. Excess weight is associated with an increased risk of many types of cancer but is also a factor in other non-communicable diseases as well [5].

\section{Obesity and Cancer}

Cancer is a major public health problem worldwide and is the second leading cause of death in the United States. In the United States alone, 18,078,957 new cases of cancer were diagnosed in 2018 and there were 9,555,027 cancer related deaths [11]. Many of these occurrences were related to obesity. According to the National Cancer Institute, (NCI) every year there are about 28,000 new cancer diagnoses in men and about 72,000 in women that are linked directly to overweight and obesity [12].

A recent report from the American Cancer Society states that, globally, more than 544,000 cancer diagnoses were attributed to excess weight in 2018 [12]. In fact, the current impact of obesity on public health is a major concern around the globe. Obesity has been shown to be a significant risk factor for numerous types of cancer [13], however, overweight individuals also have higher incidents of type-2 diabetes, high blood pressure, and heart disease.

The association between obesity and cancer has been well established in human populations [13] and people who are obese

*Correspondence to: Mary Jane Miller, University of Guam, School of Education, Foundations and Educational Research, Mangilao, Guam 96923, USA, E-mail: mjmiller@triton.uog.edu

Key words: cancer, risk factor, overweight, obesity, diet, fast food, aerobic exercise, muscle-building exercise, sugar, health, BMI

Received: March 06, 2019; Accepted: March 25, 2019; Published: March 30 2019 
generally have a greater risk of a variety of cancer types. Being overweight or obese is linked to a higher risk of at least 13 different types of cancer $[1,2]$. These cancers include breast cancer, especially in women who have been through menopause, colon, rectum, endometrium, esophagus, kidney, pancreas, and gallbladder [14].

To the list of 13 cancers associated with obesity presented by the National Cancer Institute, the Cancer Research Center adds womb, liver, ovarian, thyroid, myeloma, and meningioma as cancers related to unhealthy weight. Both the NCI list and the Cancer Research list included two of the most frequently diagnosed types of cancer (breast cancer and cancers of the bowel) as well as three types of cancer known to be the most difficult to treat (pancreatic, esophageal and gallbladder cancers). Cancers related to excessive weight account for fully $40 \%$ of all cancers in the U.S., and recent studies indicate that fat around a person's midsection may be particularly dangerous [15].

The good news is that the total number of new cancer cases in the United States has dropped overall since the 1990s. The bad news is that there has been a notable increase in cancers related to overweight and obesity during the same time period [16].

The American Cancer society reports that more than 60,000 young adults aged 20 to 39 are diagnosed with cancer each year in the U.S. and that about $4 \%$ of all cancer diagnoses occur in people in this age range. The report goes on to say that about 9,000 young adults die from cancer each year. In fact, cancer is the fourth leading cause of death in this age group, behind accidents, suicide, and homicide [17]. It should be noted that the report further says that, although young women are more likely to be diagnosed with cancer than are young men, the likelihood of dying from cancer is the same for both. In fact, among females, cancer is the leading cause of death from disease in this age group, and, among males, it is second only to heart disease [18].

\section{How obesity affects cancer}

It should be noted that just because someone is overweight doesn't necessarily mean that they will develop cancer. However, if a person is overweight, they are more likely to get cancer than if they are a healthy weight. The Cancer Research Center explains that "extra fat in the body doesn't just sit there, its active, sending out signals to the rest of your body. These signals can tell cells in our body to divide more often..." Unchecked cell division can lead to cancer [19].

Obese people often have chronic low-level inflammation, which, over time, can damage DNA and lead to cancer. Individuals who are overweight or obese are more likely than normal weight individuals to have conditions that promote or directly cause chronic local inflammation. Chronic inflammation is a known risk factors for a number of types of cancers. For example, obesity is a risk factor for an individual developing gallstones. Having gallstones is a condition characterized by chronic gallbladder inflammation, and a history of gallstones is a strong risk factor for gallbladder cancer [20].

Fat tissue has also been shown to produce excess amounts of estrogen. High levels of estrogen are associated with increased risks of several types of cancer including breast, endometrial and ovarian [20].

\section{Factors contributing to obesity}

Awareness of the importance of lifestyle factors in the relationship between obesity and cancer has continued to gain prominence [13]. Understanding the role that obesity plays in contributing to cancer risk, it is important to note factors that may contribute to obesity. Many factors can contribute to weight gain and obesity among today's youth and this study looks at three: consumption of fast food and sugar sweetened beverages and frequency of exercise.

One long term investigation, the Coronary Artery Risk Development in Young Adults (CARDIA), showed that people who ate fast food two or more times per week had an average weight gain of 10 pounds more than study participants who ate fast food less than once a week [21]. A study by Miller, La Brunda, La Brunda and Amin found that more than half of their participants who routinely ate fast food 4 or more times per week were overweight or obese. In a recent report, Darcey states that the consumption of fast food has increased dramatically in the last four decades and that the increase in calorie intake as a result is a leading factor in the current rates of obesity [22].

Consumption of sugar sweetened beverages has also been cited as a risk factor for obesity. A recent study by Yoshida and Simoes says that obesity rates among American youth have tripled since the 1980s and that this rise in obesity rates parallels the rise in the consumption of sugar sweetened beverages [23]. A fact sheet listing affects of sugar sweetened beverages says that people who consistently consume these beverages have a $60 \%$ greater chance of becoming obese [24].

Lack of sufficient exercise has long been thought to play a role in the occurrence of obesity. Most health professionals tout the benefits of exercise as a part of a healthy lifestyle because of its positive impact on overall health including cardiovascular disease and a variety of cancers [12]. While one recent study provides evidence that exercise can mitigate the effects of obesity in older women [25], the rest of the population is not faring as well. Some current research indicates that the rate at which Americans are exercising is higher than ever, but even as the rate of reported exercise rises, the rate of obesity continues to climb [26]. However, the positive impact on overall health attributed to frequent exercise still remains a prominent factor. The National Cancer Institute states that there is substantial evidence that higher rates of exercise lower the risk of several types of cancer including colon, breast and endometrial. Its further states that a sedentary lifestyle significantly increases the risk of cancer [14].

\section{Obesity and cancer among university students}

Obesity rates among young adults have gradually increased over the last 50 years, but have risen significantly in recent decades. For those venturing off to college for the first time, the newfound freedom and independence can be a time of physical, intellectual and emotional growth and maturity. It can, however, also be a time of serious weight gain. A study by Searing weighed and measured 131 freshmen in their first month of college and again at the end of their senior year. During the four years, $70 \%$ of the students gained weight and the percent of students categorized as overweight or obese increased from $18 \%$ to $31 \%$ by the time of graduation [24]. Racette, et al. [27] reported similar findings in their 2005 study of 764 freshmen and sophomores. However, by 2018 , a report titled The State of Obesity 2018 states that $35.7 \%$ of young people are not just overweight, but are obese [28].

With the understanding of harms that excess weight can inflict on human health, particularly in light of the rise of obesity related cancers, researchers are looking for factors that may contribute to the increase in average body weight. Although Campbell suggests that factors such as stress and calories from alcohol may play a role among college students, Carter (2012) suggests that the greatest influence may be late nights and easy access to fast food. In Preventing the Freshman 15, Janeway concludes that college students are gaining weight and developing poor health habits partially because of diet and exercise behaviors [29]. 
A report by the University of New Hampshire indicates that college age adults are a widely understudied demographic in relation to the prevalence of obesity [30]. With the understanding that a high rate of obesity is found among Pacific Island populations in general, knowing that obesity is associated with cancer, and that college age students are an understudied demographic in terms of prevalence of obesity and may be especially vulnerable to weight gain, it may be particularly beneficial to universities to understand the diet and exercise habits of its students. University of Guam, an educational hub of Micronesia, may find this of particular importance.

\section{Methodology}

\section{Purpose of the study and research questions}

The purpose of this study was to examine overweight and obesity rates among the student population attending University of Guam, particularly as influenced by diet and exercise, then to look at these outcomes in light of what research shows to be the impact of obesity on the risk of cancer. The ultimate goal is to address possible behavioral changes that may benefit these university age students in an effort to lower potential cancer risks.

\section{Data gathering instrument}

The data-gathering instrument for this study was an on-line survey requesting for participant demographics (gender and age) and information about the participants' various diet habits that could affect weight gain. Survey items pertained to the participants' dietary and exercise habits, and two survey items asked for the participants' height and weight. The height and weight values were used to calculate the participants' BMI using the formula: [weight (lbs.)] divided by [height (in.) ] times 703 [31]. The survey items utilized a five-level Likert scale rating asking the participants to identify the frequencies of specific dietary and exercise habits from $1=$ "rarely or never" to $5=$ "seven or more times per week".

\section{Participants}

Potential participants included 3,017 students attending the University of Guam. A total of 313 students participated in the study. This sample size represented a $95 \%$ confidence level with a $5 \%$ margin of error. The sample $(\mathrm{N}=313)$ was comprised of University of Guam students who responded to the study's online survey questionnaire. Of the 313 participants, 133 (42\%) were males, and 180 (58\%) were females. Most of the participants (92\%) were 18 to 30 years old $(n=288)$. In the remaining age categories, 20 participants $(6 \%)$ were 31 to 40 years old, 4 participants (1\%) were 41 to 50 years old, and 1 participant $(0.3 \%)$ was 51 years or older.

\section{Data collection}

Students in classes from academic divisions across the University were invited to participate in the survey via e-mail and face-to-face requests. Each participant was asked to complete a survey that would take approximately 10 minutes. A total of 313 surveys were complete and useable for this study.

\section{Data analysis}

Data analysis was done using the Statistical Package for the Social Sciences (SPSS) software, version 20. For each survey item, descriptive statistics were presented to provide a snapshot of the participants' BMI categories and their responses using frequencies, percentages, and means. In order to determine the relationship between dietary and exercise habits and weight, a Chi-Square Test of Independence was employed. In a chi-square test, the statistical analysis examines the relationship or the association between two categorical variables, and the statistical results can also show the significance and strength of the relationship between the variables [32]. To test for a $95 \%$ level of confidence, the alpha level was set at 0.05 . If a significance was determined, then the strength of any association between the variables was determined by the resulting correlation coefficient as follows: 0 to .1 little if any association, .1 to .3 low association, .3 to .5 moderate association, and $>.5$ high association.

\section{Results}

\section{BMI weight categories}

A recent study utilizing University of Guam students looked at the impact of dietary intake on BMI and obesity. This study provides evidence of a number of dietary habits that influence students' body weight [33].

This study looked at participant's BMI as a measure of overweight and obesity. BMI is interpreted using standard weight categories that are applied for all age categories and for both males and females (CDCP, 2011). These weight categories included: underweight $(\mathrm{BMI}<18.5)$, normal weight (BMI of 18.5 to 24.9), overweight (BMI of 25.0 to 29.9) and obese (BMI $\geq 30.0)$. A breakdown of the participants' BMI by these weight categories and by gender is shown in Table 1 .

Based on the participants' BMI, close to half of the participants were normal weight with a few even underweight $(49.6 \%)$, while half of the participants were overweight or obese (50.5\%). By gender, a significantly larger percentage of males (65\%) than females $(39 \%)$ were overweight or obese. Likewise, a significantly larger percentage of females (55\%) than males were in the normal weight range. A slightly higher number of females (6\%) than males $(2 \%)$ were underweight.

Numerous research studies have concluded that individuals with an elevated BMI have a much higher risk of developing a variety of cancers than those who have a normal BMI, and the greater the excess weight, the greater the cancer risk (Stone T, McPherson M, Darlington L G, 2018; Klein, Sarah, 2018; Centers for Disease Control and Prevention, October 3,2017). Based on the results of this survey just over $50 \%$ of students at University of Guam report they are overweight and about half of these judge themselves obese. This number presents a significant potential for future instances of cancer.

\section{Fast food intake}

Determining potential contributors to obesity is important in order to form useful suggestions for the prevention of obesity's contribution to future cancer diagnoses. In looking for possible reasons for the rate of reported overweight and obesity, students were asked about their fast food intake and their exercise habits.

The survey items used a five-level Likert scale rating. Table 2 provides descriptive statistics of the participants' responses for three survey items, fast food, take-out food and sugar beverages $(\mathrm{N}=313)$.

Table 1. Frequency and Percentages of Participants' BMI (N=313)

\begin{tabular}{|c|c|c|c|}
\hline BMI & \multicolumn{2}{|c|}{$\mathbf{n \%}$} & N\% \\
\hline & Males (n=133) & Females (n=180) & Group (N=313) \\
\hline Underweight & $3(2 \%)$ & $10(6 \%)$ & $13(4.2 \%)$ \\
\hline Normal weight & $43(32 \%)$ & $99(55 \%)$ & $142(45.4 \%)$ \\
\hline Overweight & $47(35 \%)$ & $35(19 \%)$ & $82(26.2 \%)$ \\
\hline Obese & $40(30 \%)$ & $36(20 \%)$ & $76(24.3 \%)$ \\
\hline
\end{tabular}


Fast food intake had a mean occurrence of $68 \%(\mathrm{M}=2.96)$ with most of the participants indicating they eat fast food 1 to 3 times or more per week. The mean value for frequency of take-out food was $48 \%$ $(\mathrm{M}=2.46)$, with almost half of the participants stating they eat takeout food 1-3 times or more per week.

The chi-square analysis revealed an association exists between BMI and two food type intakes: fast food $\left(X^{2}(12)=39.30, p=.00\right)$ and sugar sweetened beverages $\left(X^{2}(12)=25.40, p=.01\right)$. The chi-square statistic values were statistically significant $(p \leq .05)$; therefore, an association exists between fast food and sugar sweetened beverage intake and BMI. The correlation coefficient showed a low association between fast food and BMI $(V=.21)$ and sugar beverage and BMI $(V=.20)$.

\section{Exercise}

Frequency of aerobic exercise had a mean value of 3.5 with just over $27 \%$ of the participants stating that they perform aerobic exercise 3 to 4 times per week. Of the 313 participants, 64 , almost $20 \%$ state that they perform aerobic exercise 5 or more times per week. In contrast, just under $27 \%$ said that they never do any aerobic exercise. The remaining 80 participants $(25.56 \%)$ report that they perform aerobic exercise once or twice per week (Table 3).

Muscle-building or weight-training exercises had a mean value of 3.88 but, by far, the greatest number of participants, $128(26.84 \%)$ of 313 surveyed stated that they never participate in this type of exercise. Only about $13 \%$ reported that they do muscle-building activities 5 or more times per week and $65(20.76 \%)$ participants said they do so 3 to 4 times per week. Eighty survey participants (25.56\%) stated that they do muscle-building exercises once or twice per week.

The chi-square analysis showed that an association exists between BMI and frequency of muscle-building/weight-training exercise but not for aerobic exercise. The chi-squared value for aerobic exercise was: $\left(X^{2}(12)=3.8317, p=.05029\right)$. For muscle-building or weight training exercise the statistical value was: $\left(X^{2}(12)=31.513, p=.001\right)$. The chi-square value for aerobic exercise was not significant at the $(p$ $\leq .05)$, however, the chi-square value for muscle-building exercise was statistically significant at ( $p \leq .05)$; therefore, for this population, an association exists between muscle-building/weight-training exercises and BMI, but not for aerobic exercise and BMI.

\section{Conclusion}

Based on the findings of this study, students at University of Guam are similar to college students across the nation: overweight and obesity are widespread. A 2014 study by Kang et al. [34] reports similar findings to this study: factors contributing to overweight were poor quality diet and low rates of exercise. With the association that has been established between obesity and cancer [13], the presence of excess weight puts many UOG students in a higher risk category for cancer.

Some factors that contribute to the obesity rate at UOG are the frequent consumption of fast food and sugar sweetened beverages as well as the lack of sufficient muscle-building exercise. Taking into consideration that the student data is self-reported, therefore there is a probability that the amount of exercise is overestimated and weight is underestimated, makes the outcomes of this study even more stark: obesity is widespread; obesity is associated with cancer; many students have a higher risk of cancer due to behavioral habits that lead to excess weight.

A number of recommendations can be offered for lowering cancer risk and obesity. Recommendations from the cancer center at Mayo Clinic and from the American Cancer Society have many items in common. Some of the recommendations address elements that were not discussed in this study, but will be included as additional useful information.

The mayo Clinic recommends 1) Eat a healthy diet, 2) maintain a healthy weight, 3) protect yourself from the sun, 4) avoid tobacco, 5) get regular medical care, 6) get vaccinated, and 7) avoid risky behaviors (sex and needle use) [35]. Recommendations from the American Cancer Society are 1) get to and stay at a healthy weight, 2) exercise regularly, 3) eat a healthy diet, 4) get regular cancer screenings, 5) avoid tobacco, and 6) limit alcohol (American Cancer Society, 2017).

Both lists describe an overall healthy lifestyle where a healthy diet, normal weight and plenty of exercise are mainstays. Other factors mentioned on both lists include regular health/cancer screenings and avoidance of tobacco.

To reduce cancer risk and maintain a healthy diet and normal weight the Mayo Clinic (2018) makes the following recommendations:

- Eat plenty of fruits and vegetables. A diet based on fruits, vegetables and other foods from plant sources such as whole grains and beans is beneficial.

- Avoid obesity. Eating lighter and leaner by choosing fewer highcalorie foods, including refined sugars as well as reducing fat from animal sources helps with healthy body weight.

- If you choose to drink alcohol, do so only in moderation. The risk of various types of cancer, including breast, colon, lung, kidney and liver, increases with the amount of alcohol you drink and with the length of time you've been drinking alcohol regularly.

Table 2. Fast Food and sugar beverage intake reported by university students [33]

\begin{tabular}{|c|c|c|c|c|c|c|c|}
\hline \multirow[b]{2}{*}{ Type of Food Intake } & \multicolumn{7}{|c|}{ N (\%) } \\
\hline & $\begin{array}{c}1 \\
\text { Rarely or Never }\end{array}$ & $\begin{array}{c}2 \\
\text { 1-3 times per } \\
\text { month }\end{array}$ & $\begin{array}{c}3 \\
\text { 1-3 times per week }\end{array}$ & $\begin{array}{c}4 \\
\text { 4-6 times per week }\end{array}$ & $\stackrel{5}{7+\text { times per week }}$ & Mean & SD \\
\hline 1. Fast food & $24(8 \%)$ & $71(23 \%)$ & $130(42 \%)$ & $70(22 \%)$ & $18(6 \%)$ & 2.96 & 0.99 \\
\hline 2. Take-out food & $41(13 \%)$ & $123(39 \%)$ & $114(36 \%)$ & $33(11 \%)$ & $2(0.6 \%)$ & 2.46 & 0.87 \\
\hline 3. Sugar sweet beverages & $44(14 \%)$ & $38(12 \%)$ & $83(27 \%)$ & $71(23 \%)$ & $77(25 \%)$ & 3.32 & 1.34 \\
\hline
\end{tabular}

Table 3. Frequency of exercise among university students

\begin{tabular}{|c|c|c|c|c|c|c|c|}
\hline \multirow[b]{2}{*}{ Type of Exercise } & \multicolumn{7}{|c|}{$\mathbf{N}(\%)$} \\
\hline & $\begin{array}{c}1 \\
\text { none }\end{array}$ & $\begin{array}{c}2 \\
1-2 \text { times per week }\end{array}$ & \begin{tabular}{|c|}
3 \\
3-4 times per week
\end{tabular} & \begin{tabular}{|c|}
4 \\
5-6 times per week
\end{tabular} & \begin{tabular}{|c|}
5 \\
$7+$ times per week
\end{tabular} & Mean & SD \\
\hline 1. Aerobic Exercise & $84(26.84 \%)$ & $80(25.56 \%)$ & $86(27.47 \%)$ & $45(14.37 \%)$ & $19(6.07 \%)$ & 3.50 & 1.22 \\
\hline 2. Muscle-building or weight-training & $128(40.89 \%)$ & $80(25.56 \%)$ & $65(20.76 \%)$ & $31(9.90 \%)$ & $10(3.19 \%)$ & 3.88 & 1.16 \\
\hline
\end{tabular}


- Limit processed meats. A report from the International Agency for Research on Cancer, the cancer agency of the World Health Organization, concluded that eating large amounts of processed meat can slightly increase the risk of certain types of cancer.

- Physical activity counts, too. In addition to helping to control weight, physical activity on its own might lower the risk of breast cancer and colon cancer.

The American Cancer Society (2017) adds that a number of studies have shown that eating a variety of different fruits and vegetables along with whole grains, and fish or poultry is linked with a lower risk of developing a variety of cancers. On the other hand, studies also show that eating more processed and red meat is associated with a higher risk of developing certain cancers. Their suggestions include the following.

- Eating at least $2 \frac{1}{2}$ cups of vegetables and fruits each day

- Eating less red meat (beef, pork, and lamb) and consuming less processed meat such as bacon, sausage, luncheon meats, and hot dogs

- Choosing breads, pastas, and cereals that are made from whole grains instead of from refined grains, and opting for brown rice instead of white

\section{- Eating fewer sweets}

Physical activity may help to maintain a healthy weight but has also been shown to lower the risk of several types of cancer, including breast, endometrium, prostate, and colon cancer. It also reduces the risk of other serious diseases such as diabetes and heart disease.

- Adults should get at least 150 minutes each week of moderateintensity activity which is about equal to a brisk walk, or 75 minutes every week of vigorous activity which is activity that makes your heartbeat and breathing faster and makes you sweat. Preferably the exercise is spread throughout the week.

- Kids should get at least 1 hour of moderate- or vigorous-intensity activity every day. Preferably kids get should vigorous activity at least 3 days a week.

Following these recommendations would help University of Guam students reduce their cancer risk by maintain an overall healthy lifestyle that includes a normal body weight and sufficient exercise.

\section{References}

1. Klein S (2018) Thirteen types of cancer linked to overweight. Retrieved March 22, 2019.

2. NIH National Cancer Institute. (n.d.) (2019) Cancer's association with overweight and obesity. Retrieved March 19, 2019.

3. Miller MJ, La Brunda A, La Brunda M, Amin N (2013) Food for thought: Why are we still getting fat? Proceedings of Clute International Academic Conference. Clute Institute: Paris, France.

4. Pacific Daily News [PDN] (2014) Pacific islands top list of world's fattest countries. pp: 17.

5. Cancer.net. (2019a) Obesity, Weight and Cancer Risk. Retrieved March 23, 2019.

6. Centers for Disease Control and Prevention [CDCP] (2011) About BMI for adults. Retrieved March 19, 2019

7. BMI Calculator.org. (2009) What is BMI? Retrieved from March 21, 2019.

8. World Health Organization (2013) Obesity and overweight. Retrieved March 19, 2019.

9. Carter S (2012) College students' weighty choices bring obesity to forefront. The Spokesman-Review. Retrieved March 24, 2019.
10. Bovard J (2018) Starvation issues at universities? The real college problem is obesity. Retrieved March 22, 2019.

11. Bray F, Ferlay J, Soerlomataram I, Siegel R, Torre L, (2019) September Global Cancer Statistics. Retrieved March 20, 2019.

12. National Cancer Institute (2017) Physical Activity and Cancer. Retrieved March 21, 2019.

13. Stone T, McPherson M, Darling L (2018) Obesity and Cancer: Existing and New hypotheses for a causal connection. Retrieved March 20, 2019.

14. NIH National Cancer Institute (2015) Risk factors for cancer. Retrieved March 19, 2019.

15. Cancer Research UK (2018a) Does obesity cause cancer? Retrieved March 19, 2019.

16. Department of Nutrition Harvard U (2012) Fact Sheet: Sugary Drinks, Supersizing, and the Obesity Epidemic. Retrieved March 20, 2019.

17. American Cancer Society (2016) Exercise linked with lower risk of 13 types of cancer Retrieved March 21, 2019.

18. American Cancer Society (2018) Diet, Exercise and Your Cancer. Retrieved March $21,2019$.

19. Cancer Research UK (2018b). How does cancer cause obesity? Retrieved March 19, 2019.

20. NIH National Cancer Institute (2017) Obesity Facts. Retrieved March 22, 2019

21. Health and Wellness (2011) Fast food statistics and obesity in America. Retrieved March 24, 2019

22. Darcey M (2017) Retrieved March 20, 2019.

23. Yoshida Y, Simoes E (2019) Sugar-sweetened beverages, obesity, and type 2 diabetes in children and adolescents. Retrieved March 20, 2019.

24. Searing L (2012) Weight gain is not limited to first year of college, according to new study. The Washington Post. Health and Science. Washington, DC.

25. NewsMax Health (2019) Exercise can offset obesity in Senior Women. Retrieved March 24, 2019

26. Wynn M (2018) By the Numbers: Obesity and Exercise. Retrieved March 20, 2019.

27. Racette SB, Deusinger SS, Strub MJ, Highstein GR, Deusinger RH, et al. (2005) Weight changes, exercise, and dietary patterns during freshman and sophomore years of college. J Am College Health 53: 245-251.

28. Warren M, Beck S, Rayburn J, Lipson S, Wolfe M, et al. (2018) The state of obesity: Better policies for a healthier America. Retrieved March 24, 2019.

29. Janeway J (2014) Obesity action coalition: Preventing the freshman 5, 10, 15, 40 Retrieved March 19, 2019.

30. University of New Hampshire (2007) New nutritional research indicates college students face obesity, High blood pressure, metabolic syndrome. Retrieved March 24, 2019.

31. Center for Disease Control and Prevention [CDCP] (2017) Cancers associated with overweight and obesity make up $40 \%$ of cancer diagnoses in the US. Retrieved March $20,2019$.

32. Vogt WP (2007) Quantitative research methods for professionals. Boston, MA: Pearson

33. James G, Miller MJ (2016) Impact of Food Intake Habits on Weight among University of Guam Students. J Edu Hum Develop 5: 32-39.

34. Kang J, Czart C, Malin E, Carroll A, Gidea M, et al. (2004) Latent analysis of cancer risk behaviors among US college students. Retrieved March 23, 2019.

35. Mayo Clinic (2018) Cancer Prevention: 7 tips to reduce your risk. Retrieved March $22,2019$.

Copyright: (C2019 Miller MJ. This is an open-access article distributed under the terms of the Creative Commons Attribution License, which permits unrestricted use, distribution, and reproduction in any medium, provided the original author and source are credited. 